\title{
CHRONIC DISSEMINATED HISTOPLASMOSIS WITH LESIONS RESTRICTED TO THE MOUTH: CASE REPORT
}

\author{
Antonio Carlos F. do VALLE(1), Luiz Carlos MOREIRA(1), Rodrigo ALMEIDA-PAES(2), João S. MOREIRA(1), Cláudia V. PIZZINI(2),
} Mauro de Medeiros MUNIZ(2) \& Rosely M. ZANCOPE-OLIVEIRA(2)

\begin{abstract}
SUMMARY
We report a rare case of chronic disseminated histoplasmosis with several ulcerated lesions in the oral cavity in an alcoholic patient without human immunodeficiency virus infection, with no detectable signs and symptoms of systemic disease or extraoral manifestations. Histopathological analysis revealed chronic inflammatory process with granulomas containing Histoplasma-like organisms. The isolation of Histoplasma capsulatum provided the definitive diagnosis. Treatment with itraconazole resulted in complete remission of oral lesions. As far we aware, this is the second case report of oral histoplasmosis in an HIV negative patient described in Brazil.
\end{abstract}

KEYWORDS: Histoplasmosis; Oral lesions; Fungal disease.

\section{INTRODUCTION}

Histoplasmosis is a worldwide systemic mycosis caused by Histoplasma capsulatum. Although the majority of cases present as a mild to moderate flu-like disease requiring only supportive therapy, approximately $5 \%$ of patients experience more serious pulmonary and extra pulmonary disease that can be life-threatening if diagnosis is delayed or if treatment is not initiated rapidly. Definitive diagnosis is usually made by a combination of culture, detection of the organism in tissues, measurement of antibodies, or detection of antigen ${ }^{15}$.

The course of histoplasmosis can be influenced by the immune status of the host and by their exposure to infective propagules. Asymptomatic infections are usually result from exposure of a normal host to low-level microconidia. On the other hand, heavy exposures lead to clinical disease in more than $75 \%$ of patients with normal immune system ${ }^{16}$.

Histoplasmosis is clinically classified as a primary acute pulmonary form that is usually asymptomatic; a chronic pulmonary form that occurs in the presence of underlying pulmonary disease; and a disseminated form, which occurs almost exclusively in infants, the elderly, and in debilitated or immunocompromised patients. The latter is characterized by the progressive spread of infection to extra pulmonary sites $^{16}$, and the lesions in this form may be extra pulmonary in the oral cavity or intestine. In the absence of effective cell-mediated immunity infection with $H$. capsulatum may progress to fulminating with an often fatal course. The patients affected by this disease complain of symptoms such as occasional fever, asthenia, weight loss and odynophagia related to the oral lesions ${ }^{16}$. Lymphadenopathy and lung alterations can also be found.

The oral lesions frequently are granulomatous and appear as nodular ulcerative or vegetative lesions that may be painful, localized on the oral mucosa, tongue, hard and/or soft palate, or lips. The ulcers have raised and rolled borders commonly covered by a yellow or grayish membrane, resembling carcinoma or tuberculosis ${ }^{10}$.

Disseminated histoplasmosis with oral involvement in immunocompetent patient has being rarely described around the world ${ }^{6}$ or in Brazil ${ }^{4,12,13}$. We present a case of the chronic disseminated histoplasmosis in an alcohol dependent patient, HIV negative, without other subjacent underlying disease, with lesions exclusively in the oral cavity.

\section{CASE REPORT}

A 48-year-old, smoker for thirty-five years, and alcoholic male from the urban area of Barra do Piraí - Rio de Janeiro, sought treatment at the Department of Infectious Diseases at the Instituto de Pesquisa Clinica Evandro Chagas (FIOCRUZ) for a six-month history of a painful oral lesion, dysphagia, and weight loss of approximately $6 \mathrm{~kg}$. At that time, the patient was not taking any medication and had no history of systemic disease except alcoholism. Also, the patient did not report previous blood transfusions and surgeries, as well as visits to farms or caves. General clinical examination demonstrated the patient to be thin with normal skin color. He was afebrile, well-hydrated, anicteric, noncyanotic, and without edema. No lymphadenopathy or hepatosplenomegaly was appreciated on physical examination. The

(1) Department of Infectious Diseases, Instituto de Pesquisa Clínica Evandro Chagas, Fundação Oswaldo Cruz, Rio de Janeiro, Brazil.

(2) Department of Micro-Immuno-Parasitology, Instituto de Pesquisa Clínica Evandro Chagas, Fundação Oswaldo Cruz, Rio de Janeiro, Brazil.

Correspondence to: Dr. Antonio Carlos Francesconi do Valle, Departamento de Doenças Infecciosas, Instituto de Pesquisa Clínica Evandro Chagas, Fundação Oswaldo Cruz, Av. Brasil 4365, 21045-900 Rio de Janeiro, RJ, Brasil. E-mail: afvalle@ipec.fiocruz.br 
abdomen was soft and non rigid with normal bowel sounds. Cardiac auscultation revealed regular rate and rhythm, and normal breath sound. Neurological examination did not reveal abnormalities.

The examination of the oral cavity revealed a hypomobile, indurated tongue, with firm consistency and the presence of crater-like ulcers, with inflammed base and irregular borders. This lesion was $3 \mathrm{~cm}$ in its widest diameter and was located in the right margin, extending to the dorsal surface of the tongue. The ulcer border was elevated, white, well demarcated, and hard. It was friable and bled upon scraping and was extremely painful to palpation. Another irregular, ulcerated lesion, with the same characteristics was observed in the medium lateral portion and dorsal surface of the tongue in the left side. Another lesion with irregular peripheral margin, granular surface and, painful to palpation was presented at the posterior hard palate, extending to the soft palate, tonsil pillar and uvula (Fig. 1).

The floor of the mouth had increased volume without defined limits with the ventral surface of the tongue and the adjacent structures. The sublingual carunculae were also increased, without defined shapes and were considered firm and hard upon palpation. The neck examination did not reveal lymphadenophaty.

The X-ray of the paranasal sinuses, chest, and abdominal ultrasonography did not demonstrate alterations. Antibodies to Epstein Barr virus, paracoccidioidomycosis, histoplasmosis, HTLV-1, HIV, syphilis, and cytomegalovirus were negative. An eosinophilia (8\% eosinophils) was detected in blood count. Levels of urea, creatinin, bilirubins, alkaline phosphatase, GOT, GPT and cortisol (after ACTH stimulation) were normal. Sputum direct examination was negative in three samples for fungus and alcohol-acid resistant bacillus. Hemocultures were also negative. Parasitological examination of feces by Baerman-Moraes method revealed infection by Strongyloides stercoralis. For this infection the patient has received albendazole, $400 \mathrm{mg} /$ day during three days.

Biopsy was performed on one of the tongue lesions, and palate tissue was excised. Both tissue fragments were sent for histopathological and microbiological examination. Histopathology revealed pseudoepitheliomatous hyperplasia, with granulomatous chronic inflammatory process. Furthermore, $H$. capsulatum-like yeasts were evident as demonstrated by PAS and Grocott stains.

All oral samples were submitted to mycological assessment. $\mathrm{KOH}$ mounts of all samples were negative. After 15 to 20 days of culture on Sabouraud Dextrose Agar at room temperature, white to brownish filamentous colonies were observed on the slants. Microscopic examination of slide cultures on Potato Dextrose Agar, made under appropriate biosafety conditions suggested for $H$. capsulatum research, revealed septate hyaline hyphae, with globose macroconidia, and microconidia (Fig. 2a). Conversion to oval yeast cells with single budding (Fig. 2b), and demonstration of the specific $\mathrm{H}$ and $\mathrm{M}$ exoantigens, confirmed H. capsulatum identity.
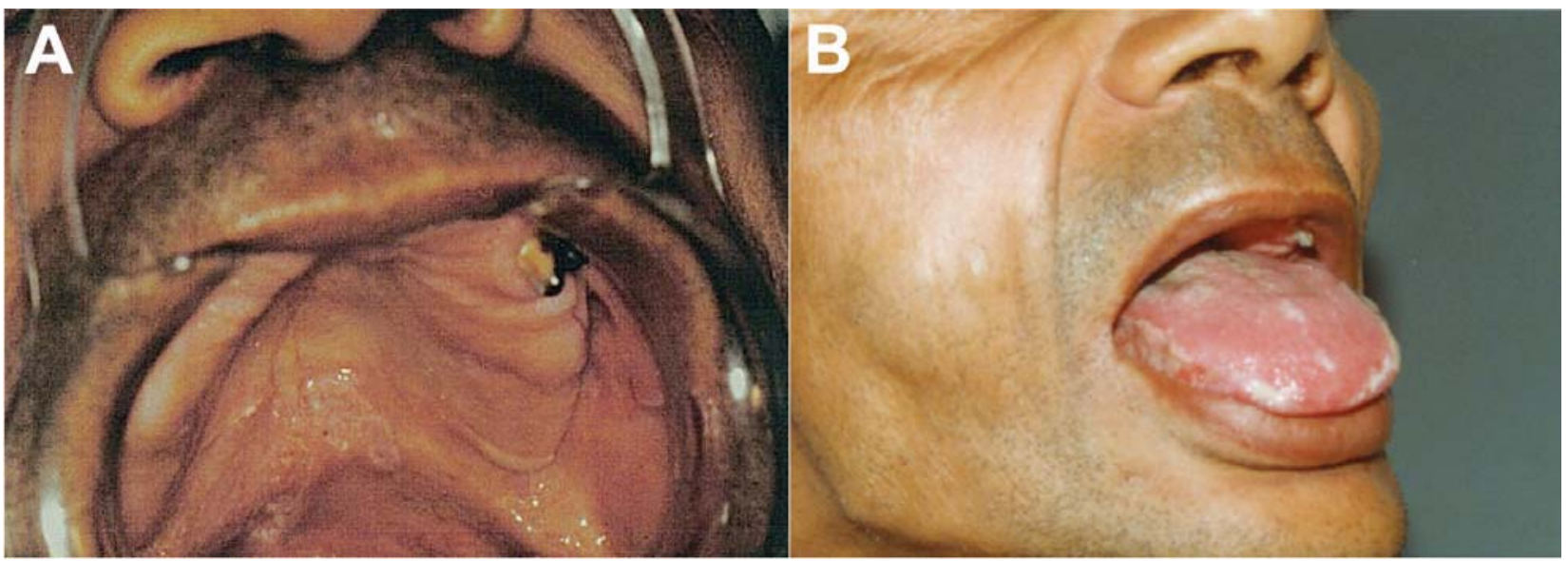

Fig. 1 - Lesions due to Histoplasma capsulatum into oral cavity of a HIV negative patient: $A$. palate lesion, $B$. tongue lesion.

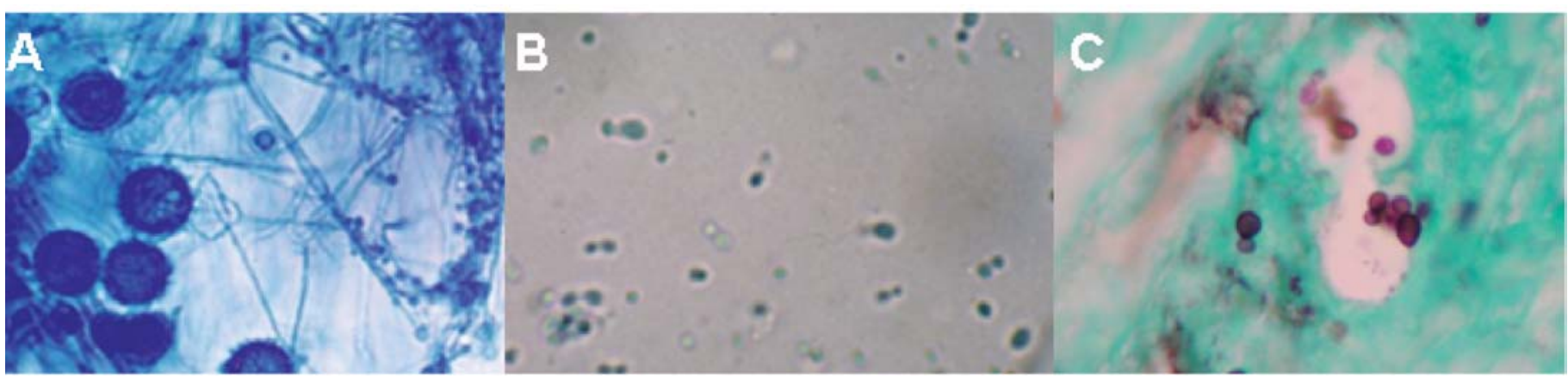

Fig. 2 - Histoplasma capsulatum stained by lactophenol cotton blue: $A$. Mould phase showing tuberculate macroconidia and microconidia, $B$. Oval, single budding yeast cells (400X). C. Grocott's stain of the tissue of the tongue, showing Histoplasma-like cells (400X). 
The patient was initially treated with oral itraconazole $100 \mathrm{mg}$ daily. After 60 days, the oral lesion had resolved completely. Two years after the onset of fungal infection, patient had no signs of recurrent oral lesions. There was no evidence of persistent $H$. capsulatum infection.

\section{DISCUSSION}

Oral manifestations of histoplasmosis, although usually described associated with the chronic disseminated form of the disease, constitute a rare event in patients HIV negative, without subjacent clinical disorders. Disseminated histoplasmosis affects mainly the phagocytic mononuclear system, with bone-marrow involvement resulting in changes in the blood picture, and often occurs in immunosuppressed patients. Enlargement of the spleen and liver may be the only gross abnormalities observed in addition to lung and oral lesions ${ }^{16}$. Oral lesions, when present, can manifest in a variety of forms, such as ulcers, erythematous or vegetative nodules ${ }^{10}$. Frequently, in cases of disseminated infection, such lesions appear as the initial clinical manifestation. Nevertheless, since 1946 few cases of apparently initial mucocutaneous histoplasmosis in patients without detectable systemic involvement have been reported ${ }^{6}$.

Histoplasmosis is worldwide in distribution. The endemic areas are located in the United States and in Latin America, and it is one of the most common systemic mycoses in Brazil. Epidemiologic surveys carried out in our country indicated that this mycosis is endemic in all areas surveyed showing high frequency of reactors in the Southeastern, geographical area where Rio de Janeiro is situated ${ }^{3}$. Although the cases of histoplasmosis have been underestimated we believe this mycosis is a very important health problem in Brazil. Acute pulmonary histoplasmosis is the most frequent clinical form reported in our country, with a dry cough, malaise and diffuse pulmonary infiltrates associated with hilar lymphadenopathy ${ }^{12}$. This usually resolves without any treatment but leaves calcified pulmonary lesions. Disseminated forms are more associated to immunodeficient subjects, notably those suffering with AIDS $^{4,12}$. A high prevalence of skin lesions and lung involvement is observed in Brazilian immunocompromised patients, in comparison with North American patients ${ }^{7}$, probably because differences in virulence between strains isolated in Brazil and United States ${ }^{2}$. The immunocompetent individuals in the United States are usually asymptomatic, or present mild, inespecific symptoms ${ }^{5,17}$, however, Brazilian patients without no predisponent risk factor can develop disseminated histoplasmosis ${ }^{14}$. Oral histoplasmosis has been frequently reported associated to HIV-seropositive patients ${ }^{4}$. As far as we aware, this is the second reported case of oral histoplasmosis in a HIV negative patient without detectable systemic involvement described in Brazil ${ }^{13}$.

Oral histoplasmosis is usually diagnosed after the discovery of lesions of the upper aero-digestive tracts, and absence of pulmonary signs. These lesions may remain the only location for a long period ${ }^{1}$, and can be misinterpreted as aphthous and/or traumatic ulcers, ulcerative necrotic gingivitis or stomatitis, other mycoses, cells squamous carcinoma and lymphomas ${ }^{6,10,15}$. The oral lesions are initially budding or wart-like and then develop into ulcerating, indurated and painful lesions ${ }^{1}$. They are resulting of hematogenous spread from an unknown infectious focus, although some investigators suggested that, when no systemic sign or symptom can be detected, oral histoplasmosis should be considered a localized disease, and treated as such ${ }^{6}$. We consider the case presented in this paper be a chronic disseminated form of the disease since the patient was alcoholic, and could be in a transient state of immunodepression, as well presented characteristic symptoms of this clinical form of histoplasmosis. The histopathology features were also consistent with those of a chronic specific infection characterized by the formation of the diffuse, small granulomas composed of histiocytes, containing variable numbers of yeast-like $H$. capsulatum revealed by PAS, and silver methenamine stain, favoring differential diagnosis with other infectious diseases ${ }^{15}$. The patient does not report any risk factor for histoplasmosis. In fact, about $20 \%$ of patients do not present any identified risk factors ${ }^{14,15}$. Nonetheless, the isolation of $H$. capsulatum in culture confirmed the diagnosis.

In the case described in this paper, the sputum analysis does not provide diagnosis. However the oral scrapping, a non-invasive procedure, revealed Histoplasma-like yeasts, as well as the $H$. capsulatum growth for confirmation of diagnosis. Therefore, we suggest that patient presenting oral attack, material from the lesions instead of sputum must be examined, for an efficient diagnosis.

The immunodiffusion test that detects antibodies against the $\mathrm{H}$ and $\mathrm{M}$ antigens of $H$. capsulatum is a reliable methodology for the presumptive diagnosis of histoplasmosis ${ }^{15}$. However, it can present low specificity in cases of immunodeficiency ${ }^{9}$. All the serum samples from this case of histoplasmosis showed negative results by immunodiffusion suggesting the need of inclusion of methodologies more sensitive and specific, as detection of antigens, for the diagnosis of histoplasmosis.

Amphotericin B is the treatment of choice for immunocompromised patients with disseminated or limited disease ${ }^{11}$. However, treatment with itraconazole was also reported as favorable ${ }^{8}$. Our studies corroborated these data, and in accordance with other authors ${ }^{12}$, suggest that, in chronic disseminated histoplasmosis, with localized lesions without detection of systemic sign or symptoms, drugs with less toxicity, such as the itraconazole, should be chosen for therapy.

\section{RESUMO}

\section{Histoplasmose crônica disseminada com lesões exclusivas na boca: relato de caso}

Reportamos um caso raro de histoplasmose crônica disseminada com diversas lesões ulceradas na cavidade oral de um paciente alcoólatra, sem o vírus da imunodeficiência humana, com nenhum outro sinal detectável ou sintomas de doença sistêmica ou manifestações extra-orais. Análise histopatológica revelou processo inflamatório crônico com granulomas contendo organismos fúngicos. O isolamento do Histoplasma capsulatum forneceu o diagnóstico definitivo. Tratamento com itraconazol resultou numa remissão completa das lesões orais. De acordo com nosso conhecimento, este é o segundo caso reportado de histoplasmose oral em um paciente HIV negativo descrito no Brasil.

\section{ACKNOWLEDGEMENTS}

The authors thank George S. Deepe for his help in revising the manuscript. 


\section{REFERENCES}

1. COIFFIER, T.; ROGER, G.; BEUST, L. et al. - Pharyngo-laryngeal histoplasmosis: one case in an immunocompetent child. Int. J. Pediat. Otorhinolaryng., 45: 177-181, 1998.

2. DURKIN, M.M.; CONNOLLY, P.A.; KARIMI, K. et al. - Pathogenic differences between North American and Latin American strains of Histoplasma capsulatum var. capsulatum in experimentally infected mice. J. clin. Microbiol., 42: 4370-4373, 2004

3. FAVA, S. Di C. \& FAVA-NETTO, C. - Epidemiologic surveys of histoplasmin and paracoccidiodin sensitivity in Brazil. Rev. Inst. Med. trop. S. Paulo, 40: 155-164, 1998.

4. FERREIRA, O.G.; CARDOSO, S.V.; BORGES, A.S.; FERREIRA, M.S. \& LOYOLA, A.M. - Oral histoplasmosis in Brazil. Oral Surg. Oral Med. Oral Path. Oral Radiol. Endod., 93: 654-659, 2002.

5. GOODWIN, R.A.; LOYD, J.E. \& DES PREZ, R.M. - Histoplasmosis in normal hosts. Medicine, 60: 231-266, 1981 .

6. MIGNOGNA, M.D.; FEDELE, S.; LO RUSSO, L.; RUOPPO, E. \& LO MUZIO, L. A. A case of oral localized histoplasmosis in an immunocompetent patient. Europ. J. clin. Microbiol. infect. Dis., 20: 753-755, 2001

7. KARIMI, K.; WHEAT, L.J.; CONNOLLY, P. et al. - Differences in histoplasmosis in patients with acquired immunodeficiency syndrome in the United States and Brazil. J. infect. Dis., 186: 1655-1660, 2002.

8. NEGRONI, R.; ROBLES, A.M.; ARECHAVALA, A. \& TABORDA, A. - Itraconazole in human histoplasmosis. Mycoses, 32: 123-130, 1989.
9. PIZZINI, C.V.; ZANCOPÉ-OLIVEIRA, R.M.; REISS, E. et al. - Evaluation of a Western blot test in an outbreak of acute pulmonary histoplasmosis. Clin. diagn. Lab. Immunol., 6: 20-23, 1999.

10. ROCHA, M.M. \& SEVERO, L.C. - Histoplasmose disseminada em pacientes com síndrome da imunodeficiência adquirida (SIDA). Estudo de 25 casos. Rev. Inst. Med. trop. S. Paulo, 36: 167-170, 1994

11. SCULLY, C.; de ALMEIDA, O.P. \& SPOSTO, M.R. - The deep mycosis in HIV infection. Oral. Dis., 3 (suppl. 1): S201-S207, 1997.

12. SEVERO, L.C.; OLIVEIRA, F.M.; IRION, K.; PORTO, N.S. \& LONDERO, A.T. Histoplasmosis in Rio Grande do Sul, Brazil: a 21-year experience. Rev. Inst. Med. trop. S. Paulo, 43: 183-187, 2001.

13. THIAGO, P.T.; SANTOS, J.I. \& STEINDEL, M. - Histoplamose em região de palato duro simulando lesão causada por Leishmania. Rev. Soc. bras. Med. trop., 31: 225229,1998

14. UNIS, G.; OLIVEIRA, F.M. \& SEVERO, L.C. - Histoplasmose disseminada no Rio Grande do Sul. Rev. Soc. bras. Med. trop., 37: 463-468, 2004.

15. WHEAT, L.J. - Laboratory diagnosis of histoplasmosis: update 2000. Semin. resp. Infect., 16: 131-140, 2001.

16. WHEAT, L.J. \& KAUFFMAN, C.A. - Histoplasmosis. Infect. Dis. Clin. N. Amer., 17: 1-19, 2003.

17. WOLF, J.; BLUMBERG, H.M. \& LEONARD, M.K. - Laryngeal histoplasmosis. Amer. J. med. Sci., 327: 160-162, 2004

Received: 4 July 2005

Accepted: 7 December 2005 